\title{
Article \\ Diagnostic Potential of Low Serum Platelet, Albumin and Prolong PT-INR for Overactive Bladder and Nocturia in Chronic Hepatitis-Related Liver Cirrhosis
}

\author{
Po-Heng Chuang ${ }^{1}\left(\mathbb{D}\right.$, Yi-Huei Chang ${ }^{2}$, Po-Jen Hsiao ${ }^{2, *} \mathbb{D}$ and Eric Chieh-Lung Chou ${ }^{2, *}$ \\ 1 Center for Digestive Medicine, Department of Internal Medicine, China Medical University Hospital, \\ Taichung City 40402, Taiwan; poheng2@yahoo.com.tw \\ 2 Department of Urology, China Medical University Hospital, China Medical University, \\ Taichung City 40402, Taiwan; yihueichang1006@gmail.com \\ * Correspondence: pojenhsiao@gmail.com (P.-J.H.); ericchou66@yahoo.com.tw (E.C.-L.C.)
}

\section{check for} updates

Citation: Chuang, P.-H.; Chang, Y.-H.; Hsiao, P.-J.; Chou, E.C.-L.

Diagnostic Potential of Low Serum Platelet, Albumin and Prolong PT-INR for Overactive Bladder and Nocturia in Chronic Hepatitis-Related Liver Cirrhosis. J. Clin. Med. 2021, 10, 2838. https://doi.org/10.3390/ jcm10132838

Academic Editors: Emilio Sacco and Matthias D. Hofer

Received: 7 May 2021

Accepted: 24 June 2021

Published: 27 June 2021

Publisher's Note: MDPI stays neutral with regard to jurisdictional claims in published maps and institutional affiliations.

Copyright: (c) 2021 by the authors. Licensee MDPI, Basel, Switzerland. This article is an open access article distributed under the terms and conditions of the Creative Commons Attribution (CC BY) license (https:// creativecommons.org/licenses/by/ $4.0 /)$.

\begin{abstract}
Overactive bladder $(\mathrm{OAB})$ is defined as urgency, usually with frequency, nocturia, and incontinence. Patients with liver cirrhosis often present with urinary complaints. The possible reason for this is fluid redistribution, which may induce $O A B$ resulting from portal hypertension and ascites. We conducted this study to investigate predictors of OAB in cirrhotic patients. A total of 164 patients with chronic viral hepatitis-related liver cirrhosis were enrolled and 158 (96.3\%) completed the Overactive Bladder Symptoms Score (OABSS) questionnaire. Age, severity of liver cirrhosis, comorbidities, serum sodium level, use of diuretics, body mass index and renal function were also recorded. In the study cohort, the prevalence of OAB was 31.01\% and the prevalence of urge incontinence (OAB wet) was $18.3 \%$. Patients with an urgency score $\geq 2$ in OABSS had a significantly lower platelet level ( $p=0.025)$ regardless of the use of diuretics. In addition, 98 patients $(62 \%)$ with nocturia and 29 patients $(18 \%)$ with urge incontinence had significantly lower levels of serum albumin ( $p=0.028$ and 0.044 , respectively). In conclusion, patients with liver cirrhosis have a high prevalence of overactive bladder. A low platelet and low serum albumin level in these patients may be predictors for overactive bladder. And longer PT-INR is also a possible biomarker for nocturia.
\end{abstract}

Keywords: overactive bladder; liver cirrhosis; nocturia; frequency; urgency; incontinence

\section{Introduction}

Over the past several decades, liver diseases and cirrhosis have risen to become one of the leading causes of death and illness worldwide. In 2017, cirrhosis caused more than 1.32 million deaths globally. The number of prevalent cases of decompensated and compensated cirrhosis globally increased to over 10.6 million and 112 million, respectively. In 2017, the age-standardized prevalence of decompensated cirrhosis and compensated cirrhosis reached 132.5 per 100,000 and 1395 per 100,000 population, respectively [1]. Liver cirrhosis is a late-stage progressive hepatic fibrosis and involves the formation of regenerative nodules. The clinical course of patients with advanced cirrhosis is often complicated by a number of important sequelae that can occur regardless of the underlying cause of the liver disease [2]. Symptoms of cirrhosis include anorexia, weight loss, weakness, fatigue, jaundice, itching, and signs of upper gastrointestinal bleeding (hematemesis, melena, bloody stool), and hepatic encephalopathy is commonly observed by hepatologists. Urinary tract infections are commonly observed in liver cirrhosis patients despite seemingly few report of such findings in the literature.

Overactive bladder $(\mathrm{OAB})$ is a storage lower urinary tract symptom (LUTS), defined by the International Continence Society (ICS) as urgency with or without urge urinary in-continence, usually with frequency and nocturia in the absence of urinary tract infections 
or other obvious pathology [3]. The prevalence of OAB is currently around $10 \%$ globally, and it is expected to keep increasing [4,5]. The Epidemiology Urinary Incontinence and Comorbidities (EPIC) study [6] reported similar prevalence rates of OAB in men (10.8\%) and women $(12.8 \%)$, with an increasing prevalence with advanced age. The reported prevalence rates of $\mathrm{OAB}$ and urge incontinence in subjects aged between 60 and 69 years in the EPIC study were $18 \%$ and $2.5 \%$, respectively. Studies have shown that OAB seems to be more prevalent in East Asian people. A multi-country study conducted in China, Taiwan and South Korea found that the overall prevalence of OAB in adults aged $\geq 40$ years was $20.8 \%$ (22.1\% for women, $19.5 \%$ for men) [7]. Yu et al. reported an age-adjusted prevalence rate of $\mathrm{OAB}$ in patients aged 60 to 69 years of $16.9 \%$ in a questionnaire survey from 1827 community dwelling adults in a Taiwan population [8]. OAB is associated with a poor quality of life, diurnal fatigue, decreased concentration, lower performance at work, and accidents because of cognitive and motor impairment [9]. Therefore, an increasing amount of research has focused on $\mathrm{OAB}$ and the resulting health consequences. Due to high prevalence of both $\mathrm{OAB}$ and liver cirrhosis among East Asians, we conducted an observational study to assess the association between liver cirrhosis and $\mathrm{OAB}$ and to explore the diagnostic potential liver function test parameters in chronic liver cirrhosis patients susceptible to LUTS.

\section{Materials and Methods}

This study enrolled 164 patients with chronic viral hepatitis-related liver cirrhosis who attended the outpatient hepatogastroenterology clinics at a tertiary referral medical center between March 2014 and June 2018. Patients with primarily neurogenic voiding dysfunction, stress urinary incontinence, refractory urinary tract infection, urolithiasis, proven interstitial cystitis/bladder pain syndrome, bladder or prostate malignancy, benign prostate enlargement or LUTS under medication control or prostatic surgery, and bladder outlet obstruction such as urethral stricture were precluded from enrollment. The Institutional Review Board and the Ethics Committee of the hospital (CMUH102-REC2-038) approved this study.

All patients received face-to-face consultation from the same urologist (Eric ChiehLung Chou) to discuss the outcomes of the self-administered questionnaire, the Over-active Bladder Symptoms Score (OABSS).The OABSS is a four-item questionnaire developed by Homma et al., and is used to assess the symptoms of OAB. The total OABSS score is the sum of scores from these four questions: daytime frequency (score 0-2), nighttime frequency (score 0-3), urgency (score 0-5), and urgency incontinence (score 0-5) [10]. Of the 164 patients, $158(96.3 \%)$ completed the questionnaire, but six did not respond due to malaise, refusal, or dementia.

Age, history of diabetes mellitus, hypertension, and dyslipidemia, severity of liver cirrhosis (Child Pugh classification, including hypoalbuminemia, hyperbilirubinemia and ascites), serum sodium level, use of diuretics, body mass index (calculated as the body weight in kilograms divided by the square of the body height in meters) and renal function (serum creatinine) were also collected and evaluated. Patients with an urgency score $\geq 2$ (once a week or more) were considered to have OAB. Significant nocturia was defined as voiding two times or more during the night, with each void preceded and followed by sleep (i.e., a score of nighttime frequency $\geq 2$ ). Once patients with cirrhosis develop progressive abdominal heaviness and pressure as well as shortness of breath due to clinically apparent ascites, they were prescribed with furosemide $20 \mathrm{mg}$ and spironolactone $50 \mathrm{mg}$ daily.

The data are expressed as mean \pm standard deviation for continuous variables or as a number and percentage for categorical variables. All comparisons of patients' categorical characteristics and urinary symptoms were assessed using the Fisher's exact test. MannWhitney $\mathrm{U}$ test was used to compare the means of continuous variables such as platelet, bilirubin, PT-INR and creatinine with or without urinary symptoms. A $p$ value $<0.05$ indicates statistical significance. All statistical analyses were performed using SPSS software version 17.0 (SPSS, Chicago, IL, USA). 


\section{Results}

\section{Statistical Results}

The mean age of the 158 patients was $64.29 \pm 9.65$ years, of whom $82(51.9 \%)$ had chronic hepatitis B and $76(48.1 \%)$ had chronic hepatitis C. There were 102 males and $56 \mathrm{fe}-$ males. The mean BMI $(\mathrm{kg} / \mathrm{m} 2)$ was $25.11 \pm 4.35$. The mean serum albumin level, sodium $(\mathrm{Na})$, bilirubin, creatinine, platelet, and PT-INR of these patients were $3.85 \pm 0.63 \mathrm{~g} / \mathrm{dL}$, $136.49 \pm 3.84 \mathrm{mEq} / \mathrm{L}, 2.11 \pm 5.88 \mathrm{mg} / \mathrm{dL}, 1.24 \pm 1.35 \mathrm{mg} / \mathrm{dL}, 121.16 \pm 64.44 \times 10^{3} / \mu \mathrm{L}$, $1.16 \pm 0.19$, respectively (Table 1 ).

Table 1. Patient characteristics.

\begin{tabular}{ccc}
\hline & Type & Number \\
\hline Disease & & \\
& CHB + LC & $32(20.2 \%)$ \\
& CHB + LC + HCC & $50(31.64 \%)$ \\
& CHC + LC & $15(9.49 \%)$ \\
& CHC + LC + HCC & $61(38.60 \%)$ \\
\hline Child-Pugh classification & & \\
& A (score5-6) & $122(77.2 \%)$ \\
& B (score7-9) & $29(18.35 \%)$ \\
Gender & C (score10-15) & $7(4.43 \%)$ \\
\hline Age $($ years $)$ & Male & $102(64.56 \%)$ \\
BMI $\left(\mathrm{kg} / \mathrm{m}^{2}\right)$ & Female & $56(35.44 \%)$ \\
Albumin $(\mathrm{g} / \mathrm{dL})$ & & Mean \pm standard \\
Na(Sodium $(\mathrm{mEq} / \mathrm{L})$ & & $64.29 \pm 9.65$ \\
Bilirubin $(\mathrm{mg} / \mathrm{dL})$ & $25.11 \pm 4.35$ \\
Creatinine $(\mathrm{mg} / \mathrm{dL})$ & $3.85 \pm 0.63$ \\
Platelet $\left(\times 10^{3} / \mu \mathrm{L}\right)$ & $136.49 \pm 3.84$ \\
PT-INR & $2.11 \pm 5.88$ \\
\hline & & $1.24 \pm 1.35$ \\
& & $121.16 \pm 64.44$ \\
& & $1.16 \pm 0.19$
\end{tabular}

CHB: chronic hepatitis B, LC: liver cirrhosis, HCC: hepatocellular carcinoma, CHC: chronic hepatitis C, BMI: Body Mass Index, PT-INR: Prothrombin time international normalized ratio.

In Table 2, 49 of 158 (31.01\%) liver cirrhosis patients had OAB according to OABSS. Ninety eight of the 158 patients $(62 \%$ ) had significant nocturia symptoms (nocturia score $\geq 2$ ) which were $61.77 \%$ in males and $62.50 \%$ in females. Fifty patients $(31.65 \%)$ had urgency symptoms (urgency score $\geq 2$ ) which were $29.41 \%$ in males and $35.71 \%$ in females. 29 patients $(18.30 \%$ ) had urge incontinence (urge incontinence score $\geq 2$ ) which were $16.67 \%$ in males and $21.42 \%$ in females. There was no significant difference between genders in symptoms of frequency, nocturia, urgency, and urge incontinence.

Age was a dependent risk factor for urgency (urgency and non-urgency, $68.36 \pm 10.59$ years and $63.35 \pm 8.79$ years, $p=0.002$ ), nocturia (nocturia and non-nocturia $67.15 \pm 9.02$ years and $61.32 \pm 9.62$ years, $p<0.001$ ) and urge incontinence (urge incontinence and non-urge incontinence $69.76 \pm 10.40$ years and $63.85 \pm 9.17$ years, $p=0.008)$. A lower platelet level was noted in patients with an urgency score $\geq 2(p=0.025)$. Patients with nocturia and urge incontinence also had significantly lower serum albumin levels $(p=0.028$ and 0.044 , respectively). The international normalized ratio (INR) of prothrombin time was relatively longer in the patients with nocturia than in those without $(p=0.01)$ (Table 3). 
Table 2. Results of the OABSS questionnaire between genders.

\begin{tabular}{|c|c|c|c|c|c|}
\hline Variable & Score & Total $(n=158)$ & Men $(n=102)$ & Women $(n=56)$ & $P$ Value \\
\hline \multirow[t]{3}{*}{ Frequency } & & & & & 0.4052 \\
\hline & 1 & $57(36.08 \%)$ & $38(37.25 \%)$ & $19(33.93 \%)$ & \\
\hline & 2 & $10(6.33 \%)$ & $3(2.94 \%)$ & $7(12.50 \%)$ & \\
\hline \multirow[t]{4}{*}{ Nocturia } & & & & & 0.1521 \\
\hline & 1 & $48(30.38 \%)$ & $30(29.41 \%)$ & $18(32.14 \%)$ & \\
\hline & 2 & $45(28.48 \%)$ & $24(23.53 \%)$ & $21(37.50 \%)$ & \\
\hline & 3 & $53(33.54 \%)$ & $39(38.24 \%)$ & $14(25.00 \%)$ & \\
\hline \multirow[t]{6}{*}{ Urgency } & & & & & 0.5758 \\
\hline & 1 & $20(12.66 \%)$ & $11(10.78 \%)$ & $9(16.07 \%)$ & \\
\hline & 2 & $16(10.13 \%)$ & $9(8.82 \%)$ & $7(12.50 \%)$ & \\
\hline & 3 & $12(7.59 \%)$ & $7(6.86 \%)$ & $5(8.93 \%)$ & \\
\hline & 4 & $15(9.49 \%)$ & $9(8.82 \%)$ & $6(10.71 \%)$ & \\
\hline & 5 & $7(4.43 \%)$ & $5(4.90 \%)$ & $2(3.57 \%)$ & \\
\hline \multirow[t]{6}{*}{ Urge incontinence } & & & & & 0.4040 \\
\hline & 1 & $21(13.29 \%)$ & $10(9.80 \%)$ & $11(19.64 \%)$ & \\
\hline & 2 & $12(7.59 \%)$ & $6(5.88 \%)$ & $6(10.71 \%)$ & \\
\hline & 3 & $7(4.43 \%)$ & $4(3.92 \%)$ & $3(5.36 \%)$ & \\
\hline & 4 & $9(5.70 \%)$ & $6(5.88 \%)$ & $3(5.36 \%)$ & \\
\hline & 5 & $1(0.63 \%)$ & $1(0.98 \%)$ & $0(0.00 \%)$ & \\
\hline Overactive bladder & & $49(31.01 \%)$ & $30(29.41 \%)$ & $19(33.93 \%)$ & 0.8891 \\
\hline
\end{tabular}

Table 3. Risk factors for urgency, nocturia and urge incontinence in the patients with liver cirrhosis.

\begin{tabular}{|c|c|c|c|c|c|c|c|c|c|}
\hline & $\begin{array}{l}\text { Urgency } \\
(n=108)\end{array}$ & $\begin{array}{c}\text { Non-Urgency } \\
\quad(n=50)\end{array}$ & $\begin{array}{c}P \\
\text { Value }\end{array}$ & $\begin{array}{l}\text { Nocturia } \\
(n=98)\end{array}$ & $\begin{array}{c}\text { Non- } \\
\text { Nocturia } \\
(n=60)\end{array}$ & $\begin{array}{c}P \\
\text { Value }\end{array}$ & $\begin{array}{c}\text { UI } \\
(n=29)\end{array}$ & $\begin{array}{c}\text { Non-UI } \\
(n=129)\end{array}$ & $\begin{array}{c}P \\
\text { Value }\end{array}$ \\
\hline Age & $68.36 \pm 10.59$ & $63.35 \pm 8.79$ & 0.002 & $67.15 \pm 9.02$ & $61.32 \pm 9.62$ & $<0.001$ & $69.76 \pm 10.40$ & $63.85 \pm 9.17$ & 0.008 \\
\hline BMI & $26.26 \pm 5.30$ & $24.61 \pm 3.81$ & 0.084 & $25.45 \pm 4.46$ & $24.92 \pm 4.31$ & 0.521 & $26.28 \pm 5.72$ & $24.85 \pm 3.99$ & 0.153 \\
\hline Albumin & $3.77 \pm 0.67$ & $3.88 \pm 0.62$ & 0.322 & $3.76 \pm 0.62$ & $3.99 \pm 0.63$ & 0.028 & $3.63 \pm 0.61$ & $3.89 \pm 0.63$ & 0.044 \\
\hline Sodium & $134.37 \pm 2.39$ & $137.48 \pm 3.30$ & 0.143 & $135.83 \pm 2.36$ & 137. $62 \pm 2.58$ & 0.382 & $137.55 \pm 3.09$ & $136.96 \pm 3.16$ & 0.376 \\
\hline Bilirubin & $2.03 \pm 5.95$ & $2.14 \pm 5.88$ & 0.912 & $2.20 \pm 6.17$ & $1.97 \pm 5.43$ & 0.812 & $2.31 \pm 6.48$ & $1.18 \pm 0.76$ & 0.351 \\
\hline $\mathrm{Cr}$ & $1.15 \pm 0.95$ & $1.27 \pm 1.51$ & 0.594 & $1.36 \pm 1.51$ & $1.03 \pm 1.03$ & 0.129 & $1.03 \pm 0.54$ & $1.28 \pm 1.48$ & 0.370 \\
\hline Platelet & $105.78 \pm 52.79$ & $128.50 \pm 68.50$ & 0.025 & $119.45 \pm 64.07$ & $124.69 \pm 65.98$ & 0.651 & $124.74 \pm 66.9$ & $105.93 \pm 51.5$ & 0.158 \\
\hline PT-INR & $1.16 \pm 0.13$ & $1.16 \pm 0.21$ & 0.859 & $1.19 \pm 0.22$ & $1.11 \pm 0.13$ & 0.01 & $1.15 \pm 0.14$ & $1.16 \pm 0.20$ & 0.819 \\
\hline Gender & & & 0.415 & & & 0.927 & & & 0.460 \\
\hline Male & $30(58.57 \%)$ & $72(69.32 \%)$ & & $63(64.29 \%)$ & $39(65.00 \%)$ & & $17(16.67 \%)$ & $85(83.33 \%)$ & \\
\hline Female & $20(41.43 \%)$ & $36(30.68 \%)$ & & $35(35.71 \%)$ & $21(35.00 \%)$ & & $12(21.43 \%)$ & $44(78.57 \%)$ & \\
\hline Ascites & & & 0.610 & & & 0.016 & & & 0.643 \\
\hline yes & $40(80 \%)$ & $90(83.33 \%)$ & & $75(78.57 \%)$ & 55 (91.67\%) & & $107(82.31 \%)$ & $23(79.31 \%)$ & \\
\hline no & $10(20 \%)$ & $18(16.67 \%)$ & & $23(23.47 \%)$ & $5(8.33 \%)$ & & $22(16.92 \%)$ & $6(20.69 \%)$ & \\
\hline Diuretics & & & 0.805 & & & 0.064 & & & 0.602 \\
\hline yes & $42(84 \%)$ & $89(82.40 \%)$ & & 77 (78.57\%) & $54(90.00 \%)$ & & $106(80.82 \%)$ & $25(19.08 \%)$ & \\
\hline no & $8(16 \%)$ & $19(17.59 \%)$ & & $21(21.43 \%)$ & $6(10.00 \%)$ & & $23(85.19 \%)$ & $4(14.81 \%)$ & \\
\hline $\begin{array}{l}\text { Diabetes } \\
\text { mellitus }\end{array}$ & & & 0.710 & & & $P=0.638$ & & & 0.277 \\
\hline yes & $39(78 \%)$ & $87(80.56 \%)$ & & 77 (78.57\%) & $49(81.67 \%)$ & & $105(\%)$ & $21(\%)$ & \\
\hline no & $11(22 \%)$ & $21(19.44 \%)$ & & $21(21.43 \%)$ & $11(18.33 \%)$ & & $24(\%)$ & $8(\%)$ & \\
\hline Hypertension & & & 0.617 & & & $P=0.469$ & & & 0.742 \\
\hline yes & $38(76 \%)$ & $78(72.22 \%)$ & & $70(71.43 \%)$ & $46(76.67 \%)$ & & $94(\%)$ & $22(\%)$ & \\
\hline no & $12(24 \%)$ & $30(27.78 \%)$ & & $28(28.57 \%)$ & $14(23.33 \%)$ & & $35(\%)$ & $7(\%)$ & \\
\hline
\end{tabular}

BMI: Body Mass Index, Cr: creatinine, PT-INR: Prothrombin time international normalized ratio, UI: urge incontinence.

\section{Discussion}

Our study found that a high proportion of patients with liver cirrhosis have OAB. Many medical disorders can cause OAB, such as cerebrovascular disease, cardiovascular disease, hypertension, diabetes mellitus, sleep disorders and metabolic syndrome [11-14]. Our research found that the prevalence of OAB in patients with liver cirrhosis was 31.01\%, with a prevalence rate of urge incontinence of $18.30 \%$, which is higher than in the age-matched general population of Taiwan. If some interference factors such as DM and hypertension are ruled out, the prevalence of $\mathrm{OAB}$ in patients with liver cirrhosis was $32.30 \%$, with a prevalence rate of urge incontinence of $19.30 \%$. The differences between countries and race could be related to a variety of factors, such as cultural differences, lifestyle preferences (factors such as 
obesity and caffeine consumption), and ethnicity (some nationalities may be genetically more susceptible to $\mathrm{OAB}$ than others). In our study, the proportion of $\mathrm{OAB}$ present in patients with liver cirrhosis is higher than that of the general population. One explanation relates to fluid redistribution which may result from portal hypertension, ascites and hypoalbuminemia. If these patients have concurrent leg edema or ascites, they could be taking diuretics which can cause polyuria, frequent urination or nocturia due to some postural changes.

In our research, we found that age is an independent factor for urgency, nocturia, and urge incontinence. The prevalence of nocturia (score $\geq 2$ ) was $62 \%$ in patients with liver cirrhosis with an average age of 64.29 years. In the BACH (Boston Area Community Health) survey, aging was a risk factor for nocturia, with a prevalence rate of $41.2 \%$ in patients aged 60 to 79 years. A prior study revealed a similar finding of markedly increasing prevalence of OAB in men and women with advanced age [15]. Regardless of health status, circulatory dynamics, organ function, and immune competency tend to decline with aging, resulting in a potentiation of $\mathrm{OAB}$ symptoms.

In our study, hypoalbuminemia was found to be associated with nocturia and urinary incontinence. The average serum albumin level was $3.85 \pm 0.63 \mathrm{~g} / \mathrm{dL}$ in our study, which is lower than that of the general population. A recent study reported that the functional capacity of albumin in patients with cirrhosis is impaired [16]. Liver cirrhosis may cause hypoalbuminemia because albumin is synthesized exclusively in the liver. Serum albumin levels fall as the synthetic function of the liver declines with worsening cirrhosis. Thus, serum albumin levels can be used to gauge the severity of cirrhosis. In healthy individuals, human serum albumin constitutes $50 \%$ of the plasma proteins. The functional characteristics of albumin include plasma oncotic pressure, solubility, transport and metabolism, antioxidants, immunomodulation, capillary permeability, hemostatic effects and endothelial stabilization $[17,18]$. A low serum albumin level will cause a decrease in osmotic pressure in the body, triggering the onset of compensatory diuresis in order to retain fluid homeostasis and restoration of osmotic pressure [19]. Besides, a low serum albumin level, coupled with impaired albumin function, may lead to fluid accumulation in the dependent parts of the body, from which fluids can then redistribute to the circulating volume in the case of recumbent position, resulting in nocturia. The other reason is that a low serum albumin level could be viewed as an indicator of impairment in hepatic protein synthesis, which also impacts the synthesis of cholinesterase, an enzyme involved in acetylcholine hydrolysis. This condition has been reported to result in delayed removal of the large acetylcholine burst secreted by the parasympathetic nerve terminals in the bladder when the micturition reflex is activated [20]. Sugaya et al. also reported a significant association between the serum levels of cholinesterase and albumin [21]. The presence of a cholinergic effect will cause a bladder spasm, resulting in frequency and urgency.

Poor liver function may lead to OAB. Prothrombin INR abnormal also reflects hepatic synthesis dysfunction. Levels of procoagulant proteins, such as prothrombin, factors II, V, VII and X, are decreased in patients with hepatic fibrosis and cirrhosis [22]. Some studies reported that poor liver function increases the risk of insulin resistance. An accumulating body of research has shown that diabetes and insulin resistance have a strong association with OAB. Hammarsten was the first to report that patients with faster growing prostates had higher insulin [23]. Uzun et al. reported that women with OAB have an increased risk for metabolic syndrome and insulin resistance [24,25]. We found that longer INR, which represents poor liver function, may relate to nocturia $(p=0.01)$.

Patients with $\mathrm{OAB}$ did have a relatively low platelet count. Thrombocytopenia has been reported to represent the more severe cases of liver cirrhosis [26]. In patients with cirrhosis, the hemostatic imbalance may tip to bleeding or thrombosis [27]. Therefore, although patients may suffer from spontaneous bleeding episodes [28], cirrhosis is also associated with hypercoagulation, and patients are at a higher risk for venous thromboembolism, portal vein thrombosis, and pulmonary embolism [27]. Bladder ischemia and hypoxia caused by hypercoagulation may be important factors leading to OAB [29]. 
Thus, a lower platelet count may be a predictor of the severity of urgency in patients with liver cirrhosis.

The possible pathophysiology of $\mathrm{OAB}$ is the involvement of a chronic inflammatory process in the bladder $[30,31]$. Progression of liver cirrhosis is caused by dysregulation of the balance mechanism governing immune system activation/homeostasis, which triggers a continuous inflammatory process and is mediated by secretion of various cytokines capable of causing liver fibrosis and cell death. Presence of hepatic and systemic injury is associated with a high production of pro-inflammatory cytokines such as Interleukin(IL)$1 \beta$, Tumor Necrosis Factor (TNF)- $\alpha$, IL-6, IL-17, as well as anti-inflammatory cytokines, IL-10 and transforming growth factor (TGF)- $\beta$ [32]. Many organs exhibit physiological changes due to inflammation, and recent studies have suggested that chronic inflammation plays a role in the pathophysiology of OAB syndrome. OAB could also be a subtype of neurogenic inflammation. [33] A decreasing concentration of serum albumin and dysfunction of albumin in cirrhotic patients will impair the functioning of antioxidants and immunomodulation $[17,18]$, which may then exacerbate the inflammatory process of urinary bladder.

This is the first clinical study on the association between viral hepatitis-related liver cirrhosis and OAB. However, there are several limitations to this study. First, this study was performed at a single institute, and further large-scale studies are needed to support our finding. Second, we did not include an age-matched control group. Third, we only collect OABSS in these patients and the voiding diary, uroflowmery, and other urodynamic studies of them were lacking, so the voiding dysfunction of patients cannot be evaluated. [34] Third, selection bias may have been present as all patients were enrolled from our outpatient department and thus may present with liver cirrhosis of relatively minor severity. Nonetheless, LUTS-related quality of life is still an important consideration in patients with a Child-Pugh grade of A and B. For patients with a Child-Pugh grade of C, achieving control of their medical condition remains the priority. Further clinical research is needed to confirm our findings.

\section{Conclusions}

There is a high prevalence of $\mathrm{OAB}$ in patients with liver cirrhosis. Low serum albumin level, low platelet and longer PT-INR, considered as reliable surrogates of hepatic synthesis dysfunction in cirrhotic patients, were shown to be associated with $\mathrm{OAB}$ and nocturia, regardless of diuretic treatment. These findings serve to raise urologists' and gastroenterologists' awareness of the co-existing disease dynamics between advanced cirrhosis and $\mathrm{OAB}$ syndrome by identifying LFT parameters of clinical importance and predictive value. An insight into this comorbid association by the multidisciplinary team will potentially drive a timely evaluation and intervention to improve LUTS-related QoL in this vulnerable patient sub-population.

Author Contributions: Y.-H.C. and P.-H.C. drafted the manuscript. P.-J.H. revised the manuscript and analyzed data. E.C.-L.C. supervised the drafting and revision of the manuscript. All authors have read and agreed to the published version of the manuscript.

Funding: This research received no external funding.

Institutional Review Board Statement: The study was conducted according to the guidelines of the Declaration of Helsinki, and approved by the Institutional Review Board of China Medical University and Hospital, Taichung, Taiwan (protocol code: CMUH103-REC2-038 and date of approval: 28 June 2013).

Informed Consent Statement: Informed consent was obtained from all subjects involved in the study and written informed consent has been obtained from the patients to publish this paper.

Data Availability Statement: Data are available from the Research Ethics Committee at China Medical University and Hospital (IRB Number: CMUH102-REC2-038) and China Medical University Hospital (DMR-104-044) for researchers who meet the criteria for access to confidential data. The 
study was designed prospectively and written informed consent was obtained from patients for both the provided treatment as well as for the use of their data in this specific study. China Medical University and Hospital Research Ethics Committee, http:/ / web.cmuh.cmu.edu.tw/2007/IRB/index.html (accessed on 28 June 2013), Address: China Medical University Hospital, 2, Yude Road Taichung, Taiwan, Phone: +886-4-22052121\#1923 1927, 1929, Fax: +886-4-22071478, Email: irb@mail.cmuh.org.tw.

Conflicts of Interest: The authors declare no conflict of interest.

\section{References}

1. Sepanlou, S.G.; Safiri, S.; Bisignano, C.; Ikuta, K.S.; Merat, S.; Saberifiroozi, M.; Poustchi, H.; Tsoi, D.; Colombara, D.V.; Abdoli, A.; et al. The global, regional, and national burden of cirrhosis by cause in 195 countries and territories: A systematic analysis for the Global Burden of Disease Study 2017. Lancet Gastroenterol. Hepatol. 2020, 5, 245-266. [CrossRef]

2. Tsochatzis, E.; Bosch, J.; Burroughs, A.K. Liver cirrhosis. Lancet 2014, 383, 1749-1761. [CrossRef]

3. Abrams, P.; Cardozo, L.; Fall, M.; Griffiths, D.; Rosier, P.; Ulmsten, U.; Van Kerrebroeck, P.; Victor, A.; Wein, A. The standardisation of terminology in lower urinary tract function: Report from the standardisation sub-committee of the International Continence Society. Urology 2003, 61, 37-49. [CrossRef]

4. Griebling, T.L. Worldwide Prevalence Estimates of Lower Urinary Tract Symptoms, Overactive Bladder, Urinary Incontinence, and Bladder Outlet Obstruction. BJU Int. 2011, 108, 1138-1139. [CrossRef] [PubMed]

5. Irwin, D.E.; Milsom, I.; Kopp, Z.; Abrams, P.; Artibani, W.; Herschorn, S. Prevalence, Severity, and Symptom Bother of Lower Urinary Tract Symptoms among Men in the EPIC Study: Impact of Overactive Bladder. Eur. Urol. 2009, 56, 14-20. [CrossRef] [PubMed]

6. Irwin, D.E.; Milsom, I.; Hunskaar, S.; Reilly, K.; Kopp, Z.; Herschorn, S.; Coyne, K.; Kelleher, C.; Hampel, C.; Artibani, W.; et al. Population-Based Survey of Urinary Incontinence, Overactive Bladder, and Other Lower Urinary Tract Symptoms in Five Countries: Results of the EPIC Study. Eur. Urol. 2006, 50, 1306-1315. [CrossRef]

7. Chuang, Y.-C.; Liu, S.-P.; Lee, K.-S.; Liao, L.; Wang, J.; Yoo, T.K.; Chu, R.; Sumarsono, B. Prevalence of overactive bladder in China, Taiwan and South Korea: Results from a cross-sectional, population-based study. LUTS Low. Urin. Tract Symptoms 2019, 11, 48-55. [CrossRef]

8. Yu, H.-J.; Liu, C.-Y.; Lee, K.-L.; Lee, W.-C.; Chen, T.H.-H. Overactive Bladder Syndrome among Community-Dwelling Adults in Taiwan: Prevalence, Correlates, Perception, and Treatment Seeking. Urol. Int. 2006, 77, 327-333. [CrossRef]

9. Bliwise, D.L.; Foley, D.J.; Vitiello, M.V.; Ansari, F.P.; Ancoli-Israel, S.; Walsh, J.K. Nocturia and disturbed sleep in the elderly. Sleep Med. 2009, 10, 540-548. [CrossRef]

10. Homma, Y.; Yoshida, M.; Seki, N.; Yokoyama, O.; Kakizaki, H.; Gotoh, M.; Yamanishi, T.; Yamaguchi, O.; Takeda, M.; Nishizawa, O. Symptom assessment tool for overactive bladder syndrome-Overactive bladder symptom score. Urology 2006, 68, 318-323. [CrossRef]

11. Tikkinen, K.A.; Auvinen, A.; Johnson, T.M., 2nd; Weiss, J.P.; Keranen, T.; Tiitinen, A.; Polo, O.; Partinen, M.; Tammela, T.L. A systematic evaluation of factors associated with nocturia-The population-based FINNO study. Am. J. Epidemiol. 2009, 170, 361-368. [CrossRef]

12. Kupelian, V.; Shabsigh, R.; Araujo, A.B.; O’Donnell, A.B.; McKinlay, J.B. Erectile Dysfunction as a Predictor of the Metabolic Syndrome in Aging Men: Results From the Massachusetts Male Aging Study. J. Urol. 2006, 176, 222-226. [CrossRef]

13. Gourova, L.W.; Van De Beek, C.; Spigt, M.G.; Nieman, F.H.; Van Kerrebroeck, P.E. Predictive factors for nocturia in elderly men: A cross-sectional study in 21 general practices. BJU Int. 2006, 97, 528-532. [CrossRef] [PubMed]

14. Tibaek, S.; Gard, G.; Klarskov, P.; Iversen, H.K.; Dehlendorff, C.; Jensen, R. Prevalence of Lower Urinary Tract Symptoms (LUTS) in stroke patients: A cross-sectional, clinical survey. Neurourol. Urodyn. 2008, 27, 763-771. [CrossRef]

15. Potts, J.M.; Payne, C.K. Urinary Urgency in the Elderly. Gerontol. 2018, 64, 541-550. [CrossRef] [PubMed]

16. Jalan, R.; Schnurr, K.; Mookerjee, R.; Sen, S.; Cheshire, L.; Hodges, S.; Muravsky, V.; Williams, R.; Matthes, G.; Davies, N.A. Alterations in the functional capacity of albumin in patients with decompensated cirrhosis is associated with increased mortality. Hepatology 2009, 50, 555-564. [CrossRef]

17. Garcia-Martinez, R.; Caraceni, P.; Bernardi, M.; Gines, P.; Arroyo, V.; Jalan, R. Albumin: Pathophysiologic basis of its role in the treatment of cirrhosis and its complications. Hepatology 2013, 58, 836-1846. [CrossRef] [PubMed]

18. Taverna, M.; Marie, A.-L.; Mira, J.-P.; Guidet, B. Specific antioxidant properties of human serum albumin. Ann. Intensiv. Care 2013, 3, 4. [CrossRef] [PubMed]

19. Cornu, J.-N.; Abrams, P.; Chapple, C.R.; Dmochowski, R.R.; Lemack, G.E.; Michel, M.C.; Tubaro, A.; Madersbacher, S. A Contemporary Assessment of Nocturia: Definition, Epidemiology, Pathophysiology, and Management-A Systematic Review and Meta-analysis. Eur. Urol. 2012, 62, 877-890. [CrossRef]

20. Nakahara, T.; Kubota, Y.; Sakamoto, K.; Ishii, K. The role of cholinesterases in rat urinary bladder contractility. Urol. Res. 2003, 31, 223-226. [CrossRef]

21. Sugaya, K.; Onaga, T.; Nishijima, S.; Miyazato, M.; Oshiro, Y.; Hokama, S.; Uchida, A.; Ogawa, Y. Relationship between serum cholinesterase level and urinary bladder activity in patients with or without overactive bladder and/or neurogenic bladder. Biomed. Res. 2007, 28, 287-294. [CrossRef]

22. Lisman, T.; Leebeek, F.W.; de Groot, P.G. Haemostatic abnormalities in patients with liver disease. J. Hepatol. 2002, 37, $280-287$. [CrossRef] 
23. Hammarsten, J.; Högstedt, B. Hyperinsulinaemia as a risk factor for developing benign prostatic hyperplasia. Eur. Urol. 2001, 39, 151-158. [CrossRef] [PubMed]

24. Uzun, H.; Zorba, O. Metabolic Syndrome in Female Patients With Overactive Bladder. Urology 2012, 79, 72-75. [CrossRef]

25. Uzun, H.; Yılmaz, A.; Kemik, A.; Zorba, O.U.; Kalkan, M. Association of Insulin Resistance with Overactive Bladder in Female Patients. Int. Neurourol. J. 2012, 16, 181-186. [CrossRef] [PubMed]

26. Witters, P.; Freson, K.; Verslype, C.; Peerlinck, K.; Hoylaerts, M.; Nevens, F.; Van Geet, C.; Cassiman, D. Review article: Blood platelet number and function in chronic liver disease and cirrhosis. Aliment. Pharmacol. Ther. 2008, 27, 1017-1029. [CrossRef]

27. Tripodi, A.; Anstee, Q.M.; Sogaard, K.K.; Primignani, M.; Valla, D.C. Hypercoagulability in cirrhosis: Causes and consequences1. J. Thromb. Haemost. 2011, 9, 1713-1723. [CrossRef]

28. Muciño-Bermejo, J.; Carrillo-Esper, R.; Uribe, M.; Méndez-Sánchez, N. Coagulation abnormalities in the cirrhotic patient. Ann. Hepatol. 2013, 12, 713-724. [CrossRef]

29. Andersson, K.-E.; Boedtkjer, D.; Forman, A. The link between vascular dysfunction, bladder ischemia, and aging bladder dysfunction. Ther. Adv. Urol. 2017, 9, 11-27. [CrossRef]

30. Compérat, E.; Reitz, A.; Delcourt, A.; Capron, F.; Denys, P.; Chartier-Kastler, E. Histologic Features in the Urinary Bladder Wall Affected from Neurogenic Overactivity-A Comparison of Inflammation, Oedema and Fibrosis With and Without Injection of Botulinum Toxin Type A. Eur. Urol. 2006, 50, 1058-1064. [CrossRef] [PubMed]

31. Apostolidis, A.; Jacques, T.S.; Freeman, A.; Kalsi, V.; Popat, R.; Gonzales, G.; Datta, S.N.; Ghazi-Noori, S.; Elneil, S.; Dasgupta, P.; et al. Histological Changes in the Urothelium and Suburothelium of Human Overactive Bladder following Intradetrusor Injections of Botulinum Neurotoxin Type A for the Treatment of Neurogenic or Idiopathic Detrusor Overactivity. Eur. Urol. 2008, 53, 1245-1253. [CrossRef] [PubMed]

32. Fry, C.H.; Chakrabarty, B.; Hashitani, H.; Andersson, K.; McCloskey, K.; Jabr, R.I.; Drake, M. New targets for overactive bladder-ICI-RS 2109. Neurourol. Urodyn. 2020, 39 (Suppl. 3), S113-S121. [CrossRef]

33. Liu, H.-T.; Jiang, Y.-H.; Kuo, H.-C. Increased Serum Adipokines Implicate Chronic Inflammation in the Pathogenesis of Overactive Bladder Syndrome Refractory to Antimuscarinic Therapy. PLoS ONE 2013, 8, e76706. [CrossRef] [PubMed]

34. Mancini, V.; Tarcan, T.; Serati, M.; Wyndaele, M.; Carrieri, G.; Abrams, P. Is coexistent overactive-underactive bladder (with or without detrusor overactivity and underactivity) a real clinical syndrome? ICI-RS 2019. Neurourol. Urodyn. 2020, 39 (Suppl. 3), S50-S59. [CrossRef] 